\title{
Simultaneous Determination of Aerosol and Thin Cirrus Optical Depths over Oceans from MODIS Data: Some Case Studies
}

\author{
J. K. Roskovensky And K. N. LiOU \\ Department of Atmospheric and Oceanic Sciences, University of California, Los Angeles, Los Angeles, California
}

(Manuscript received 20 January 2005, in final form 15 November 2005)

\begin{abstract}
The importance of separating thin cirrus and aerosols from satellite remote sensing to produce broader and more accurate fields for the determination of respective radiative forcings is highlighted. This has been accomplished through the development of a new methodology for retrieving both thin cirrus and aerosol optical depths simultaneously over oceans from the Moderate Resolution Imaging Spectroradiometer (MODIS) data. This method employs a procedure to quantify and remove the thin cirrus contribution to the observed reflectance through a correlation of visible and $1.38-\mu \mathrm{m}$ reflectances so that the aerosol signal can be extracted. Aerosol optical depths are then retrieved through comparisons with the simulated reflectances created a priori. Using the aerosol optical depth along with the specific viewing geometry and surface reflectance as pointers to locations in a lookup table of modeled reflectances, cirrus optical depth and an effective ice crystal size can be retrieved. An iterative scheme has been created that uses the retrieved effective cirrus ice crystal size to account for the effect that the particle size distribution has on the correlation of visible and $1.38-\mu \mathrm{m}$ reflectance. Retrievals of both aerosol and thin cirrus optical depths over the Atmospheric Radiation Measurement (ARM) Tropical Western Pacific (TWP) site of Nauru performed on a limited number of cases have proven to be consistent with values determined from ground measurements. Also, comparisons with the MODIS aerosol retrievals over a broad area of ocean have highlighted the potential usefulness of this procedure in increasing the amount of potential aerosol information recovered and removing the ever-present thin cirrus contamination.
\end{abstract}

\section{Introduction}

Retrievals of the microphysical properties of atmospheric constituents on a global scale during daytime have been made practical by the addition of wellcalibrated visible and near-infrared measurements by spaceborne instruments such as the Moderate Resolution Imaging Spectroradiometer (MODIS). Clouds have been shown to produce the dominant effect on the radiation budget of the earth-atmosphere system (see, e.g., Liou 1986). However, significant uncertainties exist in the detection of thin cirrus and the determination of their optical depth and composition (Roskovensky and Liou 2003). Aerosols are now being considered as the contemporary climate problem as they contain the largest uncertainties in calculating the radiative forcing of the planet (Houghton et al. 2001). To account for the

Corresponding author address: Dr. J. K. Roskovensky, Dept. of Atmospheric and Oceanic Sciences, University of California, Los Angeles, Los Angeles, CA 90095.

E-mail: jrosko@atmos.ucla.edu radiative effects of atmospheric particulates, their optical depth, size, and composition must be characterized. Aerosol optical depth retrievals are plagued by thin cirrus contamination due to the ubiquitous nature of these clouds. To obtain accurate aerosol information on a large scale, this cirrus effect must be accurately accounted for.

Tropospheric aerosols, located predominantly in the boundary layer, exist everywhere on earth to some degree. Cirrus clouds have been observed at all latitudes (McFarquhar et al. 2000; Sassen and Cho 1992) and occur on large horizontal scales and are relatively long lived (Liou 1986). Thin cirrus coverage is also widespread, especially in the Tropics. Wylie and Menzel (1999) illustrated, by analyzing 8 years of data, that semitransparent cirrus occur in $43 \%$ of the HighResolution Infrared Radiation Sounder (HIRS) observations. During the boreal summer, they found that the effective cloud fraction of clouds higher than $6 \mathrm{~km}$ was greater than $80 \%$ over Southeast Asia and the western equatorial Pacific. Aerosols and ice particles in cirrus both affect the radiation fluxes and vertical tempera- 
ture structure of the atmosphere by interacting with radiation from the sun and the earth-atmosphere system.

Tropospheric aerosols absorb and reflect the incoming solar radiation, which generally leads to a cooling of the surface by reducing the net downward solar flux. Chou et al. (2002) analyzed data from the Sea-viewing Wide Field-of-view Sensor (SeaWiFS) and obtained values of 5.9 and $5.4 \mathrm{~W} \mathrm{~m}^{-2}$ for the aerosol-induced reduction in solar flux at the surface and at the top of the atmosphere, respectively. Because of their small sizes $(\sim 1 \mu \mathrm{m})$, tropospheric aerosols affect the thermal infrared radiation field only in a minor way compared to that of their influence on solar radiation (Ackermann 1997). However, small ice crystals in thin cirrus absorb infrared energy efficiently, especially in the shorter wavelength region of the infrared window (Smith et al. 1998). As a result, cirrus cloud emissivity $\varepsilon$, which is a measure of cloud absorption and temperature, can have a pronounced influence on outgoing radiation and, hence, climate. Lohmann and Roeckner (1995) showed, using general circulation model (GCM) results, that black cirrus $(\varepsilon=1)$ warmed the entire troposphere with a maximum in the upper tropical region and increased climate sensitivity by $20 \%$, while completely transparent cirrus $(\varepsilon=0)$ cooled the troposphere and decreased climate sensitivity.

Cirrus clouds also have a detrimental effect on remote sensing of the atmosphere below the cloud from space. Mishchenko et al. (1999) concluded that cloud contamination along with calibration uncertainties are the largest source of errors in retrieving aerosol optical depth with Advanced Very High Resolution Radiometer (AVHRR) data. It would be beneficial to be able to retrieve both tropospheric aerosol and thin cirrus properties, which have comparable optical depths, by satellite remote sensing techniques when they coexist. Unfortunately, that is difficult to accomplish because the reflected sunlight signal is scattered by both types of particles simultaneously. Normally, assumptions have to be made about the aerosol distribution to retrieve cirrus cloud properties, while the assumption that no thin cirrus exists in the field of view is made in order to retrieve aerosol properties. Identifying regions of thin cirrus from satellites has remained a challenging field of research.

In this paper we present a new procedure that quantifies the optical depths of both the thin cirrus and aerosols that have been identified to exist in the same satellite field of view over the oceans. This builds on the work developed in Roskovensky et al. (2004) by adapting an iterative approach used to recalculate optical depths by taking the cirrus effective particle size into effect. The primary goal is to be able to estimate the proportion of the attenuation that each media has on the total atmospheric attenuation. A description of the data used as well as the method of generating theoretical reflectances needed to simulate the observed values is presented in section 2 . In section 3 , the retrieval method is described in detail including the specific problem of quantifying reflection off of the surface. The uncertainties pertaining to the specific retrieval method are discussed in this section also. A number of case studies associated with the available MODIS data are presented in section 4 to illustrate the capability of the retrieval method. Finally, conclusions are given in the last section.

\section{Data and models}

\section{a. Data sources}

MODIS is a scanning spectroradiometer consisting of 36 narrowband channels from 0.41 to $14.2 \mu \mathrm{m}$. Calibrated reflectance and radiance data determined at 1$\mathrm{km}$ nadir resolution was taken from the level 1-B MOD02 product, available through the NASA Goddard Earth Sciences (GES) Distributed Active Archive Center (DAAC; available online at http://daac.gsfc. nasa.gov). The following six channels were routinely used during this investigation: $0.65 \mu \mathrm{m}$ (band 1), $0.86 \mu \mathrm{m}$ (band 2), $1.38 \mu \mathrm{m}$ (band 26), $1.64 \mu \mathrm{m}$ (band 6), $8.60 \mu \mathrm{m}$ (band 29), and $11.03 \mu \mathrm{m}$ (band 31). In addition, clear-sky fields produced from many cloud detection tests were found in the MODIS Cloud Mask product (MOD35) described in Ackerman et al. (2002). Radiance from bands 29 and 31 were converted into brightness temperatures that were compared to the brightness temperature at $5 \mathrm{~km} \times 5 \mathrm{~km}$ resolution from the MODIS Cloud Properties product (MOD06; Menzel et al. 2002) for accuracy. All calculated brightness temperatures were well within $0.1 \mathrm{~K}$ of the MOD06 results. MODIS retrievals of the aerosol and cirrus optical depths were examined for comparison purposes. These data are also available from the NASA GES DAAC. Cloud property retrievals are found in the MOD06 product (King et al. 1997) and retrieved aerosol optical depths are contained in the MOD04 product (Kaufman and Tanre 1998).

The Atmospheric Radiation Measurement (ARM) program has established several Cloud and Radiation Testbeds (CART), which consist of a high concentration of atmospheric measuring instruments. Data from one location in particular, the Tropical Western Pacific (TWP) ARM CART site in the Republic of Nauru, was used in determining atmospheric conditions during the period surrounding specific MODIS overpasses. Cloud 
height and thickness were determined by using continuous millimeter-wave radar reflectivity and micropulse lidar data. Wind speed and direction were available from the balloonborne sounding system and continuous radar wind profiler data. Column water vapor amounts were obtained from microwave radiometers. These measurements were useful as inputs in modeling radiative transfer and for validation of cirrus retrievals.

\section{b. Modeling}

The radiation transfer model (RTM) that is used to simulate MODIS reflectance and transmission is a derivative of the one described in Takano and Liou (1989b), which employs the adding/doubling method. The program was designed for the computation of the transfer of solar and terrestrial radiation in an inhomogeneous atmosphere using a predetermined number of appropriate homogeneous layers. The RTM determines absorption by oxygen, ozone, carbon dioxide, methane, nitrous oxide, water vapor, and other trace gases by using the correlated- $k$ distribution method. It performs single and multiple scattering calculations by clouds and aerosols and takes Rayleigh scattering into account as well. These scattering computations are made by using appropriate phase functions of aerosols and ice clouds given the single-scattering properties that are generated according to Lorenz-Mie theory for spherical aerosols and the unified theory of light scattering developed by Liou et al. (2000) for nonspherical ice crystals. Surface reflectance is considered to be isotropic (Lambertian).

To produce the phase functions and perform the radiative transfer calculations, three aerosol parameters are needed: the extinction coefficient, which defines the optical depth; the single scattering albedo, defined as the fractional extinction due to scattering to total extinction; and the asymmetry factor, representing the relative strength of the forward scattering. Each is given for eight different relative humidity values from $0 \%-99 \%$ over the appropriate range of wavelengths to take into account the effect of water vapor uptake aerosols. For the investigation of the separation of aerosols and thin cirrus, the clean-maritime model from D'Almeida at al. (1991) was employed for scenes over the remote oceans. Seven separate ice crystal size distributions with varying effective particle sizes have been established from in situ measurements for use in the RTM to simulate cirrus reflectance. The distribution pertaining to contrail cirrus is classified with an effective crystal size of $10 \mu \mathrm{m}$ (Liou 2002; Takano et al. 1992). The effective ice crystal size is defined by the following equation:
TABLE 1. Pixel resolution and the corresponding SNR for maritime aerosols.

\begin{tabular}{clc}
\hline \hline Resolution $(\mathrm{km})$ & \multicolumn{1}{c}{$\mathrm{Ne} \Delta \tau^{*}$} & $\mathrm{SNR}$ \\
\hline $0.5 \times 0.5$ & 0.0286 & 0.51 \\
$1 \times 1$ & 0.0143 & 1.02 \\
$5 \times 5$ & 0.00286 & 5.1 \\
$10 \times 10$ & 0.00143 & 10.2 \\
$50 \times 50$ & 0.000286 & 51 \\
\hline
\end{tabular}

* $\mathrm{Ne} \Delta \tau$ represents the noise equivalent differential spectral thickness of the MODIS instrument.

$$
D_{e}=\frac{\sum_{i} V_{i} n_{i}(L) d L}{\sum_{i} A_{i} n_{i}(L) d L},
$$

which represents the ratio of the crystal volume, $V$, to its geometric projected area, $A$, on a surface perpendicular to the incident light beam, each summed across a discrete number of size bins, $i$, defined by the crystal's maximum length, $L$, containing $n_{i}(L)$ number of particles. The other six cirrus size distributions that are used possess effective ice crystal sizes that range from 23 to $123 \mu \mathrm{m}$ were taken from Rolland et al. (2000). These distributions, with concentrations given as the number of particles per cubic meter, were derived from procedures discussed in Heymsfield and Platt (1984), Takano and Liou (1989a), and from data taken during the First International Satellite Cloud Climatology Project (ISCCP) Regional Experiment (FIRE) cirrus intensive field observation and described in more detail in Rao et al. (1995).

When retrieving properties of aerosols and thin cirrus with very low optical depths the pixel resolution plays an important role in the process because it can influence the accuracy due to potential low signal to noise in each channel. Table 1 shows the resulting noise equivalent differential spectral thickness $(\mathrm{Ne} \Delta \tau)$ and signal-to-noise ratio (SNR) for maritime aerosols. The derivations of these values are fully explained in the appendix; $\mathrm{Ne} \Delta \tau$ decreases proportionally to an increase in resolution. It is clear that in order to maintain a SNR of at least 5 , a $5 \mathrm{~km} \times 5 \mathrm{~km}$ resolution is needed. This is the minimum resolution used throughout all retrievals conducted in this paper.

\section{Retrieval method}

\section{a. Surface reflectance}

The ocean-surface bidirectional reflectance is anisotropic (Morel and Gentili 1993) and can be modeled for all necessary channels by following the equation devel- 

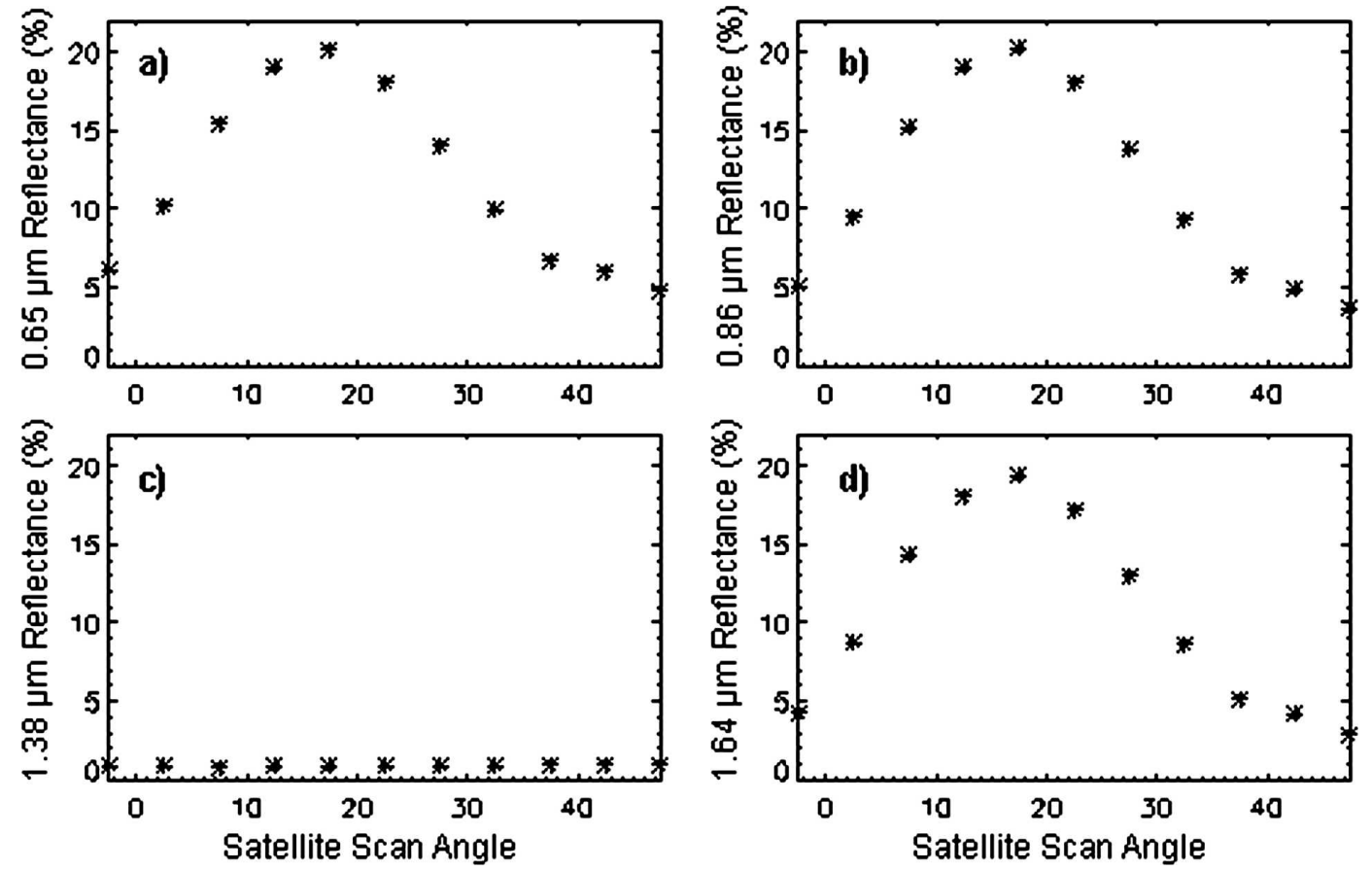

FIG. 1. Clear-sky reflectance from a 1000 line $\times 700$ pixel subsection of the 4 Oct 2001 (2350 UTC) MODIS

(Terra) granule.

oped by Koepke (1984). Since accurate surface anisotropic reflectance was difficult to produce, modified observed clear-sky reflectance was used. The surface reflectance was obtained by averaging a large amount of neighboring observed pixels that were determined to be cloud free. Pixels were considered cloud free if they possessed MODIS cloud mask clear-sky probability of above $95 \%$ (Ackerman et al. 2002) and did not indicate a presence of thin cirrus as determined by the thin cirrus parameter defined in Roskovensky and Liou (2003). This procedure identifies thin cirrus if a combined value of the ratio of the reflectance in the 1.38$\mu \mathrm{m}$ and $0.65-\mu \mathrm{m}$ bands with the $8.6-11-\mu \mathrm{m}$ brightness temperature difference, both of which are sensitive to thin cirrus, is greater than a prescribed threshold that is determined by using clear-sky information. To get the best estimate of true surface reflectance without an aerosol contribution, one clear-sky reflectance standard deviation was subtracted from the mean observed clear-sky reflectance value. This was performed under the assumption that aerosols contribute most significantly to the variance in these measurements and are correlated well to the simulated reflectance of marine aerosols with optical depths of 0.1. This assumption may not be valid in sun-glint regions where the variance of spectral reflectance is expected to increase. This modified clear-sky reflectance in four bands $(1,2,26$, and 6) is shown in Fig. 1 for the MODIS granule on 4
October 2001 (2350 UTC). Reflection was averaged in $5^{\circ}$ satellite viewing angle bins. Sun glint is apparent in all of the channels near the $17.5^{\circ}$ viewing angle that is in the forward scattering direction with respect to the sun. The smoothness of the curves illustrate that it is likely that both clouds and aerosol effects were removed with success.

\section{b. Retrieval method}

The procedure for obtaining both aerosol and thin cirrus optical depths (AOD and COD, respectively) in this paper includes an iterative process that adjusts for the influence that cirrus ice crystal size distribution has on the relationship between the visible and the $1.38-\mu \mathrm{m}$ reflectance (Roskovensky et at. 2004). A flowchart of the general procedures involved is presented in Fig. 2. Before analyzing data, reflectance lookup tables were constructed with the RTM using the aerosol and cirrus models, previously discussed, over a full range of sunsensor geometry. For this study, a cirrus cloud was inserted between 12 and $13 \mathrm{~km}$. Reflectances for the four MODIS bands 1, 2, 6, and 26 were computed using all possible combinations of eight solar and sensor zenith angles $\left(5^{\circ}, 11^{\circ}, 18^{\circ}, 26^{\circ}, 33^{\circ}, 40^{\circ}, 47^{\circ}, 54^{\circ}\right)$ and 10 relative azimuthal angles $\left(0^{\circ}, 10^{\circ}, 20^{\circ}, \ldots 180^{\circ}\right)$ along with 11 surface reflectance values $(0,0.01,0.02, \ldots, 0.10), 11$ AOD values $(0,0.05,0.1, \ldots 0.5), 11$ COD values $(0$, $0.1,0.2, \ldots 1)$, and 7 cirrus size distributions character- 


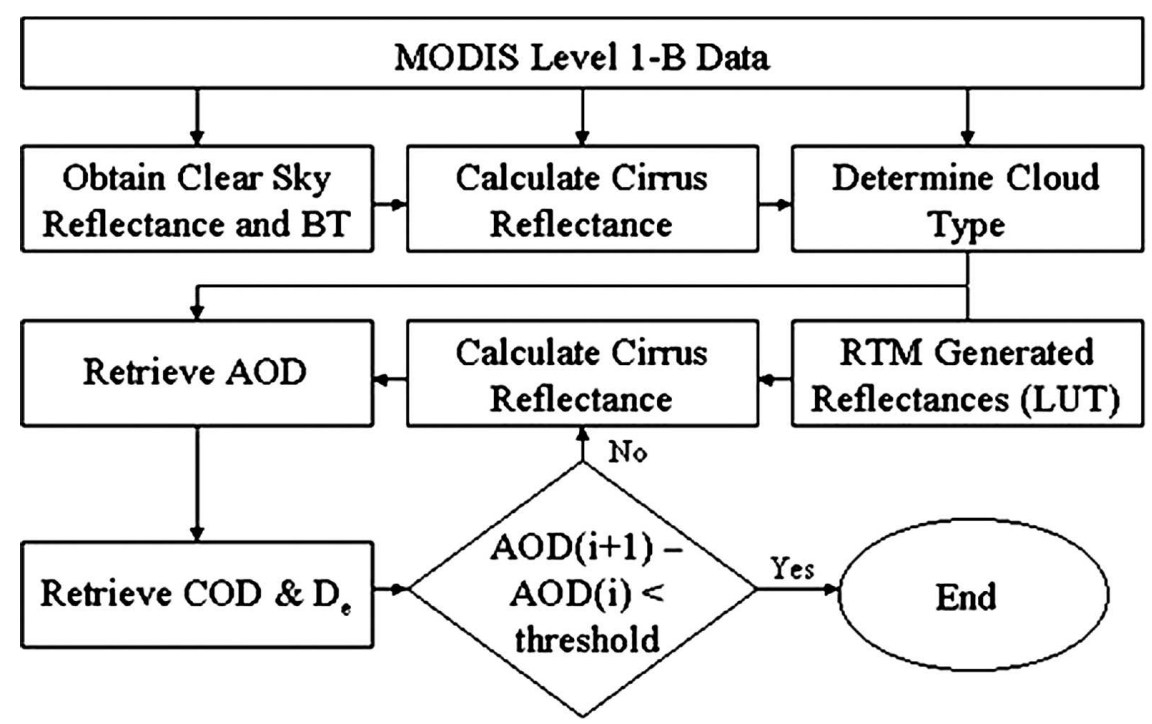

FIG. 2. Flowchart depicting the general processes involved in retrieving both the aerosol (AOD) and thin cirrus optical depths (COD) along with the ice crystal effective size $\left(D_{e}\right)$.

ized by their effective particle sizes $(10,24,30,42,75$, 94, and $124 \mu \mathrm{m}$ ). A lookup table (LUT) for each band had seven dimensions of size $8 \times 8 \times 19 \times 11 \times 11 \times$ $11 \times 7$

Assuming that most tropospheric aerosols lie below cirrus clouds, visible reflectance at the top of the atmosphere can be approximated by the sum of the three terms: cirrus reflectance $\left(r_{c}\right)$, aerosol reflectance $\left(r_{a}\right)$, and the surface reflectance $\left(r_{s}\right)$ as follows:

$$
r=r_{c}+t_{c} r_{a} t_{c}^{*}+t_{c} t_{a} r_{s} t_{a}^{*} t_{c}^{*}
$$

where $t_{c}$ and $t_{a}$ represent the cirrus and aerosol transmittance, respectively, and asterisks denote the upwelling contribution. If we examine reflectance from narrow bands with wavelength greater than $0.64 \mu \mathrm{m}$, the effects of molecular scattering can be ignored since that contribution is relatively weaker than that due to clouds and aerosols particles. Also, multiple scattering has been shown to play a secondary role for optically thin cirrus and aerosol layers. The parameterized equation denoted in Eq. (2) has been verified by using an exact adding-method radiative transfer calculation where top-of-atmosphere (TOA) reflectances are within $0.1 \%$ for small aerosol and cirrus optical depths $(<0.5)$. The reflectance due to aerosols can then be estimated by first determining the clear path reflectance, $r_{\mathrm{clr}}=t_{a} r_{s} t_{a}^{*}$; the apparent cirrus reflectance, $r_{c}^{\prime}=$ $r_{c}+r_{\text {clr }}$; and the two-way cirrus transmittance, $t_{c}^{\prime \prime}=t_{c} t_{c}^{*}$, as follows:

$$
r_{a}=\frac{r-r_{c}^{\prime}+\left(1-t_{c}^{\prime \prime}\right) r_{\mathrm{clr}}}{t_{c}^{\prime \prime}}
$$

The clear path reflectance is measured from observed reflectances as previously discussed. The two-way cirrus transmittance can be approximated by

$$
t_{c}^{\prime \prime} \approx\left(1-r_{c}\right) *\left(1-r_{c}\right)
$$

for small cirrus optical depths and when the solar and viewing angles are less than $40^{\circ}$.

Apparent cirrus reflectance in a visible band between 0.4-1.0 $\mu \mathrm{m}$ can be determined as well. Gao and Kaufman (1995) showed that visible reflectance with wavelengths less than $1 \mu \mathrm{m}, r_{c \text {,vis }}$, is correlated to the cirrus reflectance in the MODIS $1.38-\mu \mathrm{m}$ strong water vapor absorption band, $r_{c, 1.38}$, by

$$
r_{c, 1.38}=a r_{c, \mathrm{vis}}+b
$$

where $a$ is the correlation between the two bands and $b$ is dependent on absorption, scattering and reflection below the cirrus cloud level. These two parameters are both dependent on viewing geometry. Meyer et al. (2004) has shown that this correlation can be used to retrieve cirrus optical depth. The technique also forms the basis for the operational algorithm that produces visible band cirrus reflectance fields for MODIS (Gao et al. 2002). Due to water absorption in and above the cirrus clouds, reflectance in the $1.38-\mu \mathrm{m}$ band is less than that of the nonabsorbing, visible bands by a certain percent. Figure 3 shows the $1.38-\mu \mathrm{m}$ versus 0.65 $\mu \mathrm{m}$ reflectance scatterplot for all the pixels within the $0^{\circ}-5^{\circ}$ satellite viewing angle for the MODIS 22 September (2325 UTC) granule. The cirrus reflection line 


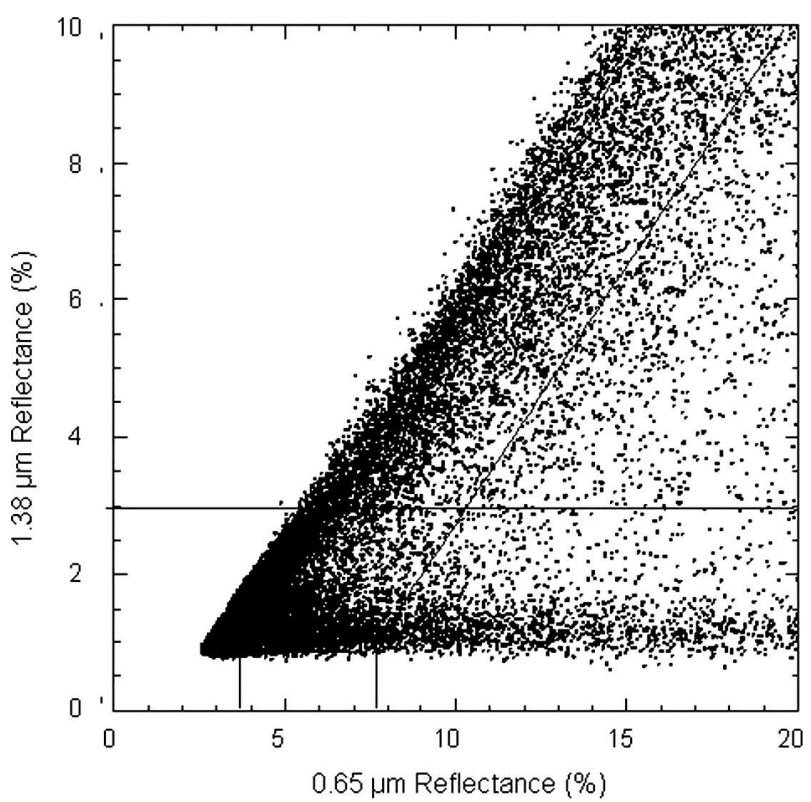

FIG. 3. Scatterplot of $1.38-\mu \mathrm{m}$ reflectance vs $0.65-\mu \mathrm{m}$ reflectance of all points in a region defined with satellite scan angle between $0^{\circ}$ and $5^{\circ}$ centered over the republic of Nauru in the TWP ARM site from the MODIS granule on 22 Sep 2001. The two lines indicate the cirrus reflectance and the aerosol/low cloud cutoff from left to right, respectively.

is shown as the left most straight line in the figure. This best-fit line was produced by using an appropriate 0.65 $\mu \mathrm{m}$ reflectance value from ninety-two $1.38-\mu \mathrm{m}$ reflection bins at $0.1 \%$ resolution from $0.9 \%$ to $10 \%$. These appropriate reflectance values were calculated by using a certain number of minimum reflection values in each bin. Nine best-fit lines were created using mean minimum reflectance values produced by altering the total number of minimum points by 10 used in each bin from 10 to 100 . Through comparisons with the observed reflectance scatter points, it was found that using 50 minimum points in each bin produced the best-fit lines that correlated most accurately. This total number was able to compensate for stray low-valued outliers while not being affected by larger reflectances from below the cirrus cloud as long as there were at least 500 reflection points in the bin. Calculated minimum points in bins with less than 500 points were not used to create the best-fit line. This means that less than $10 \%$ of the available reflectance values in each bin went into the production of the best-fit line, given that a large pool of values were on hand. Using this criteria, retrieval errors due to the creation of a best-fit line from the set of either only 10 or as much as 100 minimum points in each $1.38-\mu \mathrm{m}$ bin were less than $5 \%$ and $-4.6 \%$, respectively. Clear-sky $1.38 \mu \mathrm{m}$ was observed to be near $0.8 \%$, and was, therefore, a lower limit. The short ver- tical line attached to the bottom of the cirrus reflectance line in Fig. 3 identifies the mean clear-sky 0.65$\mu \mathrm{m}$ reflectance value calculated for that viewing angle.

Aerosol retrievals were made on groups of $5 \times 5$ pixels that were deemed to contain either clear sky or thin cirrus. A simple procedure was developed to identify single pixels containing low or opaque clouds so that they would be disregarded. First, any pixel possessing $1.38-\mu \mathrm{m}$ reflectance greater than $3 \%$ was characterized as a relatively thick high cloud. Second, if the residual reflectance in either of the nonabsorbing visible/ near-infrared channels $(0.65$ or $0.86 \mu \mathrm{m})$ was $0.5 \%$ greater than the theoretical aerosol reflectance with AOD equal to 0.5 for appropriate viewing geometry, the pixel was considered to be opaque, low cloud. This means that heavy aerosols with AOD values somewhat greater than 0.5 will appear as opaque cloud, and not be retrieved because of this test. For the scenes examined in this paper, this was not expected to be a problem, but in other regions this threshold may have to be raised. In addition, if the clear-sky probability value from the MODIS cloud mask was less than $95 \%$, the pixels were labeled as low cloud. Finally, thin cirrus was identified from the remaining pixels using the method described in Roskovensky and Liou (2003). Those pixels that remained unclassified were defined as clear.

The residual reflectance was defined as the observed reflectance minus the cirrus and surface reflectances. In Fig. 3, most of the points congregate near the two lines that intersect in the lower left portion of the plot. Points in this area are considered to be from clear sky. The horizontal scatter line of points with increasing visible reflectance is made from low clouds. The scatter line with increasing reflectance in each channel is produced from single layer cirrus cloud. The best-fit line through this scatter region represents the cirrus reflectance as a function of $1.38-\mu \mathrm{m}$ reflectance. The second line parallel to the cirrus reflectance line is the low cloud cutoff. Any pixels to the right of that line were disregarded, and those pixels in between the two lines and under the horizontal line representing $1.38-\mu \mathrm{m}$ reflectance less than $3 \%$ were used for aerosol retrievals. Pixels to the left of both lines were also used in the retrieval of AOD. If all 25 pixels from the $5 \times 5$ group were located to the left of the cirrus reflection line, than the retrieved AOD was set to 0 .

Aerosol optical depths were retrieved by matching the residual reflectances in each of the $0.65-\mu \mathrm{m}$ and $0.86-\mu \mathrm{m}$ bands to the values in their individual LUT that were correlated to viewing geometry and surface reflectance. Linear interpolation was performed between the two nearest neighbors in each LUT to obtain the AOD in each channel, which was scaled to the op- 


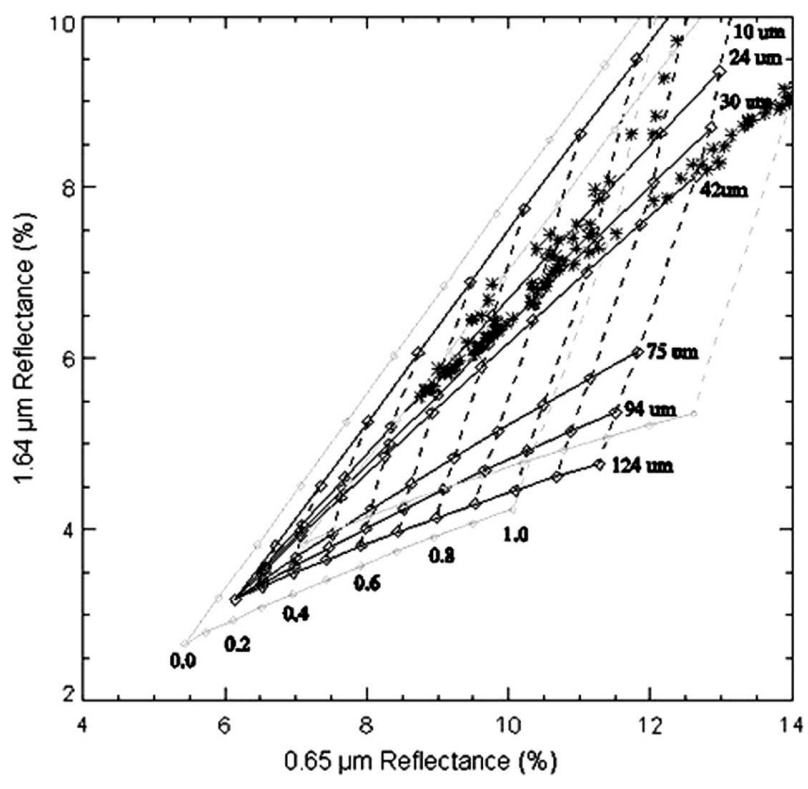

FIG. 4. Correlation between the $1.64-$ and $0.65-\mu \mathrm{m}$ reflectance is shown as a function of the effective particle size and cloud optical depth. The dark curves represent values made by a theoretical true AOD value while the light gray curves indicate curves made with the true AOD \pm 0.1 . The solid and dashed curves represent values of constant effective ice crystal size and COD, respectively. The asterisks show some observed reflectances.

tical depth at $0.55 \mu \mathrm{m}$ regardless of the wavelength used to determine its value. Averaging the two AOD values together produced the final retrieved AOD. Two bands were used in an effort to mitigate errors, but could also be used to retrieve a second aerosol parameter. Cirrus optical depth and effective ice crystal size were then retrieved for every pixel using observed reflectance in both the 0.65 - and $0.86-\mu \mathrm{m}$ bands paired with the 1.64$\mu \mathrm{m}$ reflectance by finding the best fit among precalculated reflectances in the two remaining dimensions of the LUT, once correlated to the retrieved aerosol optical depth, surface reflectance, and viewing geometry. Final COD and $D_{e}$ retrievals were produced through the averaging of the two retrieved values obtained from the $0.65-1.64-$ and $0.86-1.64-\mu \mathrm{m}$ correlations. This procedure is similar to that performed operational on MODIS data (King et al. 1997), except that the present LUT has much finer optical depth resolution (0.1) so that bilinear interpolation could be used and is intended only for thin cirrus with an optical depth less than 1. Figure 4 shows how this approach works. Lines of constant COD (dashed curves) and lines of constant $D_{e}$ intersect at large enough angles to produce a 2D grid so that the two cirrus properties can be derived. It can be seen that the reflectance in the visible band $(0.65$ $\mu \mathrm{m})$ is much more a function of COD than $D_{e}$. Reflec-
TABLE 2. Uncertainties, given in percent of the true value, in the retrieved properties given an $8 \%$ error in surface reflectance. Case 1: $\mathrm{AOD}=0.1$ and $\mathrm{COD}=0.1$; Case $2: \mathrm{AOD}=0.1$ and $\mathrm{COD}=0.5 ;$ Case $3: \mathrm{AOD}=0.2$ and $\mathrm{COD}=0.1$; Case 4: $\mathrm{AOD}$ $=0.2$ and $\mathrm{COD}=0.5$. In all cases $D_{e}=30 \mu \mathrm{m}$.

\begin{tabular}{ccc}
\hline \hline Case & AOD uncertainty & COD uncertainty \\
\hline 1 & $41 \%$ & $48 \%$ \\
2 & $41 \%$ & $9 \%$ \\
3 & $23 \%$ & $33 \%$ \\
4 & $23 \%$ & $6 \%$ \\
\hline
\end{tabular}

tance in the near-infrared band $(1.64 \mu \mathrm{m})$ at these small cirrus optical thicknesses is a function of both parameters for small particles and is less dependent on COD for large particles. The dark mesh represents LUT points determined by the true AOD value while the two light gray grids represent values determined by \pm 0.1 of true AOD value. The asterisks represent observed reflectance. Most of these points line up with the 30- $\mu \mathrm{m} D_{e}$ curve. The importance of the initial AOD retrieval is also apparent. It can be seen that slight misrepresentations in AOD can affect the retrieved COD and $D_{e}$ values. For example, it appears that an AOD error of 0.05 can cause an error of about 0.1 in COD.

\section{c. Uncertainties}

There are two inherent uncertainties in optical depth due to the specific retrieval procedure that are associated with the observed clear-sky surface reflectance and the estimated cirrus reflectance in the channels less than $1 \mu \mathrm{m}$. Although the clear-sky reflectances appear smooth with changing viewing angles, there is variation in the mean values. The largest measured standard deviation in the mean clear-sky reflectance was found to be near $8 \%$. Adjusting the cirrus reflectance line by this amount changes the value of the reflectance that is attributed to aerosols. Using this new reflectance, AOD retrievals were made and compared with true values. The second column in Table 2 shows the difference, in percent, between the true and newly derived AOD with the additional reflectance contribution for two different true AOD values of 0.1 (cases 1 and 2) and 0.2 (cases 3 and 4). The uncertainty in the retrieved AOD is obviously greater when AOD is smaller and can be $50 \%$ or larger for optically thin aerosols with values less than 0.1. The resulting COD retrievals depend upon the background aerosol optical depth and uncertainties in the AOD affect these retrieved COD values. This uncertainty in COD can be estimated by retrieving a new value based upon the incorrect AOD input and comparing it to the true COD value. This was performed for 
COD values of 0.1 and 0.5 . The four cases presented in Table 2 display all the possible combinations of the two AOD and two COD values. When cirrus optical depth is small (0.1), uncertainty in its value can be nearly $50 \%$ when the AOD value is also small. When the cirrus optical depth increases, below-cloud contributions to the top of the atmosphere reflectance is less important and the uncertainty decreases accordingly.

The correlation between cirrus reflectance in the 1.38 $\mu \mathrm{m}$ and a nonabsorbing visible/near-infrared band is slightly dependent on the effective ice crystal size. The $R_{138} / R_{\mathrm{vis}}$ slope decreases with increasing $D_{e}$. This effect is more pronounced as the cirrus cloud becomes thicker so that uncertainties grow larger with reflectance. By decreasing the slope of the cirrus reflectance line the reflectance associated with aerosols diminishes and affects the AOD retrievals. Using theoretically determined cirrus reflectance lines for effective ice crystal sizes corresponding to 30,42 , and $94 \mu \mathrm{m}$ given a background $\mathrm{AOD}$ of 0.1, uncertainties in the retrieved AOD were calculated and displayed in Fig. 5 as a function of the $1.38-\mu \mathrm{m}$ reflectance. The two curves were made by first retrieving the amount of reflectance needed to produce an AOD value of 0.1 using the cirrus reflectance line determined by $30 \mu \mathrm{m}$ as the true $D_{e}$. The decrease in this aerosol reflectance was then found by employing a new cirrus reflectance line determined using the $42-\mu \mathrm{m}$ and $94-\mu \mathrm{m} D_{e}$ values. The percentage of decrease in the aerosol reflectance was identified as the uncertainty in the retrieved AOD since reflectance is assumed to be directly proportional to optical thickness. This means that a 100\% uncertainty in AOD corresponds to a complete reduction in the aerosol reflectance and a retrieved AOD value of 0 . Uncertainties greater than $100 \%$ represent aerosol optical depths that can no longer be retrieved. Increasing $D_{e}$ from 30 to 42 $\mu \mathrm{m}$ does not produce large uncertainties, but an increase to $94 \mu \mathrm{m}$ shows that AOD retrieval becomes impossible when the $1.38-\mu \mathrm{m}$ reflectance is only slightly greater than $2 \%$. This value loosely corresponds to a COD of 0.3. In Roskovensky and Liou (2003), it was seen that the potential error in $D_{e}$ could indeed be as large as $200 \%$ owing to calibration and surface reflectance errors. On the other hand, thin cirrus is not likely to contain enough large particles to produce such a large effective size so that these uncertainty values may not have a significant physical basis. Regardless, the theoretical calculations underline the importance to accurately take the effect of the cirrus size distribution into account.

An iterative scheme has been introduced in the algorithm to remove this potential uncertainty. After the retrievals of $\mathrm{AOD}, \mathrm{COD}$, and $D_{e}$ are made, the theo-

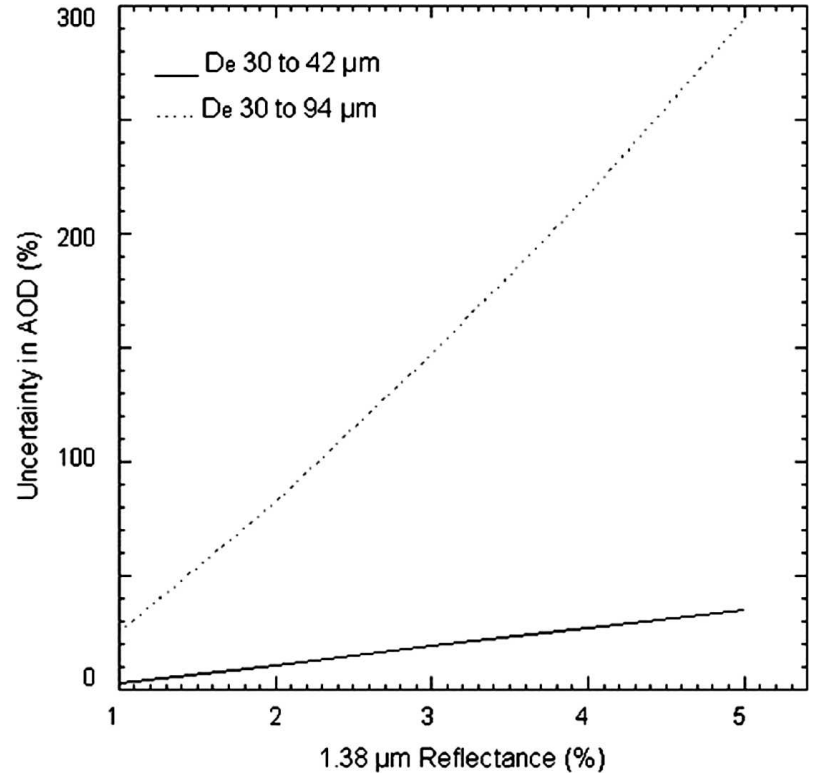

FIG. 5. Uncertainty in the AOD as a function of $1.38-\mu \mathrm{m}$ reflectance introduced by inaccurately accounting for ice crystal effective size $\left(D_{e}\right)$

retical cirrus reflectance correlations $0.65-1.38$ and $0.86-1.38 \mu \mathrm{m}$ are determined from the predefined LUT using the known viewing geometry and surface reflectance. Theoretical slopes of the correlation lines are derived for each pixel by employing the retrieved $D_{e}$ value and linearly interpolating between its two nearest $D_{e}$ neighbors in the LUT. Using the reflectance correlation slopes and the surface reflectance, new 0.65 - and $0.86-\mu \mathrm{m}$ cirrus reflectances are found. The retrieval process is then performed again. This iterative process is terminated when the granule mean AOD-retrieved value for successive iterations falls below a certain small number. The value used in this study was 0.0001 . Generally, between four and five iterations were needed to terminate the process.

The major model and procedural uncertainties are summarized in Table 3 as maximum retrieved AOD error. The maximum errors were established as a result of the specific changes in the parameter listed in the left column. Nearly all of these values, excluding those resulting from changes in aerosol effective particle size and cirrus habit, were determined through radiative transfer calculations performed over the previously defined LUT space. The effects of aerosol effective radius changes were determined by calculating the difference in the single scattering albedo for different aerosol sizes via the information presented in Mishchenko et al. (1999). Cirrus habit effects on COD were taken directly from Rolland et al. (2000) and used to determine mean AOD values. All errors are given as an absolute value 
TABLE 3. Maximum AOD uncertainties calculated when $\mathrm{AOD}=0.1$ and $\mathrm{COD}=0.1$.

\begin{tabular}{lc}
\hline \hline \multicolumn{1}{c}{ Change in parameter } & $\begin{array}{c}\text { Maximum } \\
\text { retrieved AOD } \\
\text { error }(\%)\end{array}$ \\
\hline Surface reflectance, $\rightarrow 8 \%$ error & 50 \\
Aerosol effective particle size, $0.1 \rightarrow 1 \mu \mathrm{m}$ & 10 \\
Aerosol type, maritime $\rightarrow$ continental & 2 \\
Cirrus effective crystal size, $30 \rightarrow 42 \mu \mathrm{m}$ & 10 \\
Cirrus habit, pristine $\rightarrow$ mixed $\rightarrow$ aggregate & 15 \\
Cirrus base, $8 \mathrm{~km} \rightarrow 13 \mathrm{~km}$ & 5 \\
Best-fit line location, $50 \rightarrow 100$ minimum points & 5 \\
\hline
\end{tabular}

and neither reflect the direction of the error nor a more realistic expected error.

\section{Results and discussions}

Despite being near the abundant cirrus field of the western equatorial Pacific, finding good thin cirrus cases is more difficult than expected for a variety of reasons. Due to the location of the site $\left(0.5^{\circ}\right.$ south of the equator) and the local time of the Terra overpass (1030 LST) when the sun is near its peak elevation angle, there is always sun glint present. The glint generally affects one-third of the pixels in a MODIS granule, some 500 pixels or $700 \mathrm{~km}$ longitudinally. Regions of strong sun glint prohibit the accurate retrieval of aerosol properties. To validate satellite retrievals in this region, the Aerosol Robotic Network (AERONET) Nauru sun photometer, which measures attenuation of direct sunlight in cloud-free areas in order to retrieve an AOD, and the millimeter-wave cloud radar (mmCR), which can sense very thin cirrus and penetrate reasonably thick clouds, are used. Both instruments need to be functioning properly to validate both thin cirrus and aerosols. The mmCR has a good track record and 3-h time series quick-look images as well as reflectivity data centered on a MODIS overpass were obtained from the University of Utah Web site. Three such images, dated 2330 UTC 13 September, 2325 UTC 22 September, and 2350 UTC 4 October 2001, are displayed in Fig. 6. All three show that thin cirrus with reflectivity between -30 and $0 \mathrm{dBZ}$ existed above 10 $\mathrm{km}$ over the vertically pointing radar for much of the period. The gray vertical panels represent regions of no data.

The AERONET sunphotometer data are not as complete. Available data during the MODIS (Terra) lifetime are sporadic between June to October 2001 and again from April 2002 to July 2003. Since AERONET AOD is made only during presumed clear-sky condi-

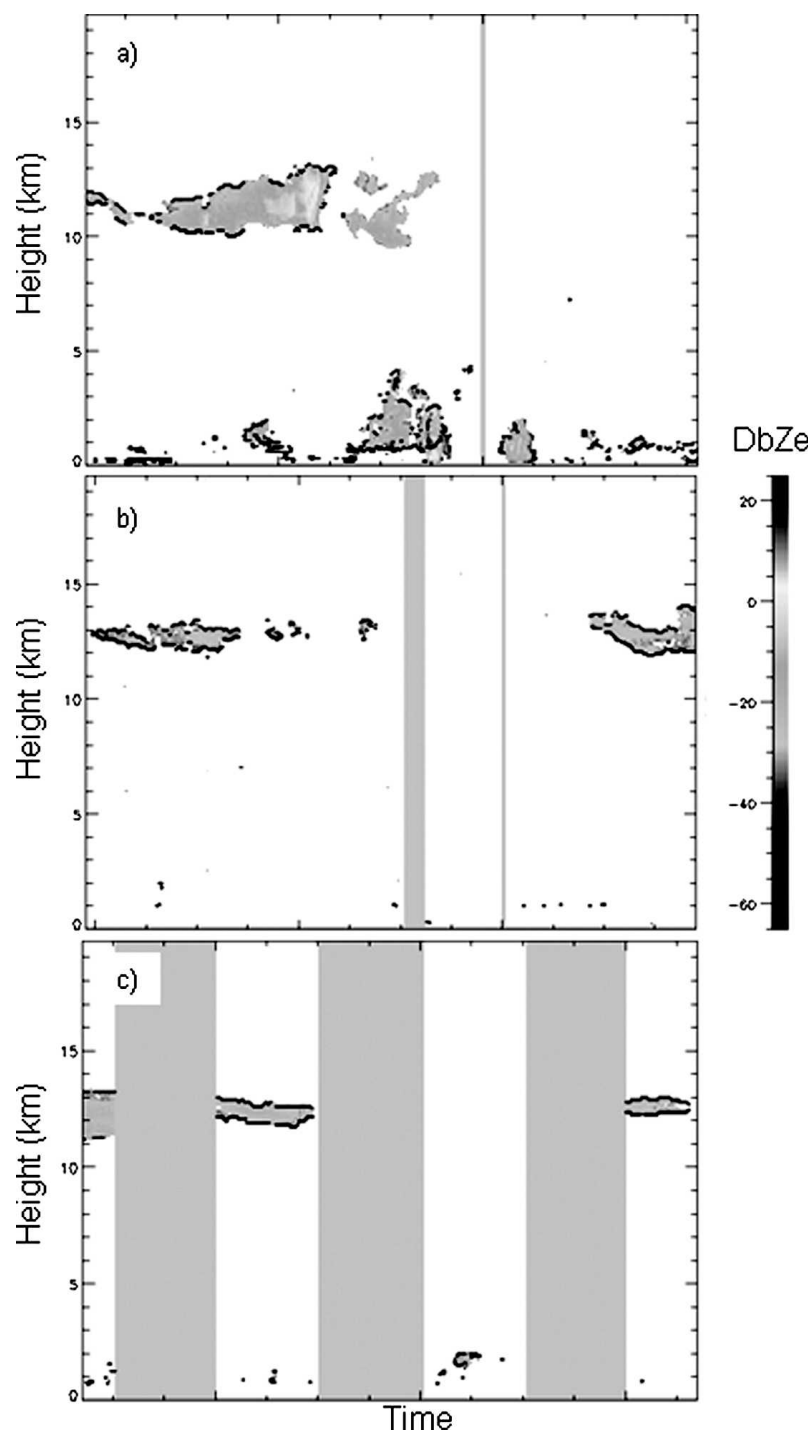

FIG. 6. Millimeter-wave radar 3-h time series originating from the Republic of Nauru and centered on the overpass of the Terra satellite at (a) 2330 UTC $13 \mathrm{Sep}$, (b) 2325 UTC $22 \mathrm{Sep}$, and (c) 2350 UTC 4 Oct 2001.

tions, any existing cirrus will not allow AERONET AOD retrievals to be made and undermine the aerosol validation efforts. Cumulus clouds, which are common in this region at all times, will also prohibit both the AERONET and satellite retrievals. To have both AERONET AOD data and mmCR detection of thin cirrus during a MODIS overpass, broken fields of thin cirrus must occur. The three scenes identified with the cloud radar in Fig. 6 show this condition. At least three AERONET AOD (calculated every 15 min) data points were available within the 3-h period when MODIS flew over in these cases. To make certain that cirrus contamination did not affect the AERONET re- 
sults, the solar zenith angle was used to determine the exact AERONET sunphotometer to sun path to make sure that there was sufficient breaks in the cirrus. Given the solar zenith and cirrus heights, it was determined that the regions in which the AERONET view path reached cirrus altitude was never more than $3 \mathrm{~km}$ (less than $5 \mathrm{~min}$ ) from the point directly above the radar where vertically pointing measurements were made. Adjustments were then made to the radar time series using the cirrus level wind to pinpoint the location where the sunphotometer line-of-sight intersected the radar time series to make certain of the clear-sky requirement. Since the millimeter-wave radar may be insensitive to subvisible cirrus, micropulse lidar data, which is generally able to detect these clouds, was also examined. Based on the observations available and our careful analyses, we are as certain as possible that the chances of cirrus contamination in the AERONET results would be extremely small.

Figure 7 shows both the 0.65 - and $1.38-\mu \mathrm{m}$ reflectance for a 1000 line $\times 700$ pixel region centered near the Republic of Nauru from the MODIS (Terra) granule 2350 UTC 4 October 2001. The rectangle in each of the images identifies a 50 pixel $\times 50$ pixel region centered on the TWP ARM site on the Republic of Nauru, where validation efforts were concentrated, is located on the right side of the image, on the edge of the MODIS defined sun glint with reflected angles ranging from $30^{\circ}$ to $35^{\circ}$. It is interesting, as well as expected, to see the sun glint disappear in the $1.38-\mu \mathrm{m}$ reflectance image in Fig. 7b. Also seen is that cirrus (bright 1.38$\mu \mathrm{m}$ reflectance regions) and opaque low cloud (bright $0.65-\mu \mathrm{m}$ reflectance regions) are intertwined throughout this small area over Nauru. Unfortunately, the 50 pixel $\times 50$ pixel region occurs in the middle of the sun glint, with reflected angles between $5^{\circ}$ and $10^{\circ}$, in the 13 September case. These data were still analyzed to determine if accurate retrievals could still be made in the presence of strong glint and because so few good validation cases have yet to be identified. The 50 pixel $\times 50$ pixel region of 22 September was located on the edge of a large cirrus field. It was also located on the edge of the sun glint region as defined by reflected angles between $25^{\circ}$ and $30^{\circ}$. No MODIS aerosol retrievals were performed inside the small rectangular region in any of the cases because of sun glint restrictions. Good retrievals from these three cases show that the new retrieval method can expand the coverage of present operational satellite aerosol retrievals by performing accurate retrievals in the presence of thin cirrus and mild sun glint.

Figure $8 \mathrm{a}$ shows the estimated cirrus reflectance in the $0.65-\mu \mathrm{m}$ band for the entire MODIS subsection in the 4 October case. The thin, wispy nature of some of a)

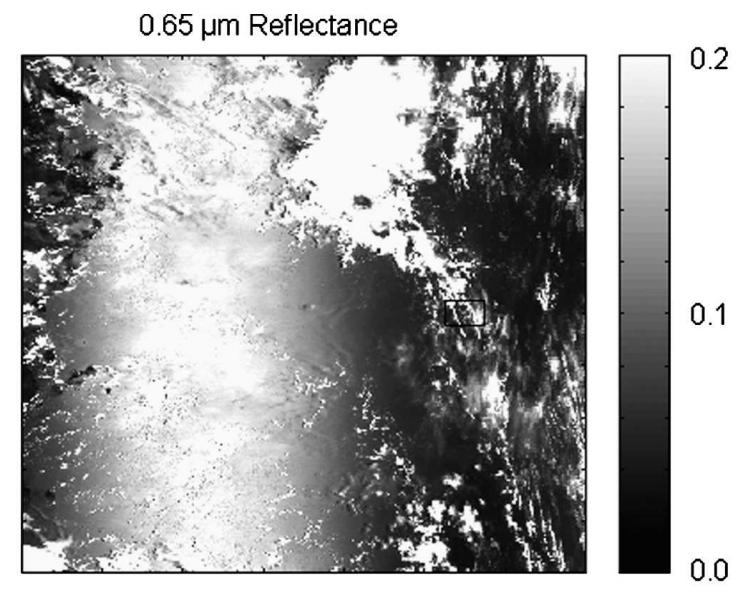

b)

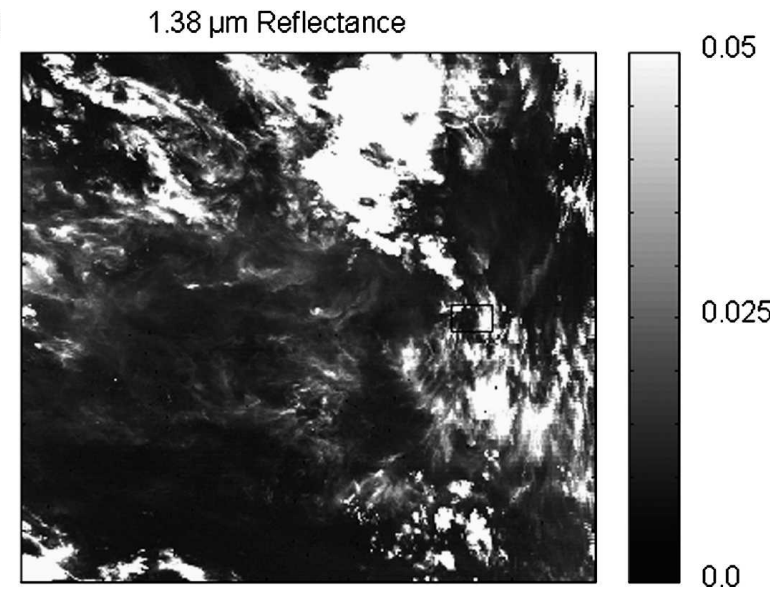

FIG. 7. MODIS (Terra) (a) 0.65 - and (b) $1.38-\mu \mathrm{m}$ reflectance for 1000 line $\times 700$ pixel subsection of the 2350 UTC 4 Oct 2001 granule.

the cirrus is apparent. Also, it is seen that the cirrus reflectance has been characterized even over strong sun glint regions. A large cirrus shield produced by deep convection is noticeable in the top, middle portion of the image. The $0.65-\mu \mathrm{m}$ reflectance with the cirrus contribution removed is displayed in Fig. 8b. The bright regions that appear in this image are due to low clouds with excessive $0.65-\mu \mathrm{m}$ reflectance. Smaller low-cloud regions can now be seen below the large cirrus shield once the cirrus component has been removed. Some of the areas where the thick cirrus of the large shield was removed appear very black, corresponding to $0 \%$ reflectance. This has resulted because too much cirrus reflectance was removed. Using the cirrus reflectance slope $\left(R_{138} / R_{065}\right)$ employed in this study for thin cirrus is inaccurate for thick cirrus because this slope is not constant across all $1.38-\mu \mathrm{m}$ reflectance values. The slope increases for larger reflectance values as pointed out in Gao et al. (2002). Thus, the $0.65-\mu \mathrm{m}$ cirrus reflectance for highly reflective cirrus clouds with the 
a)

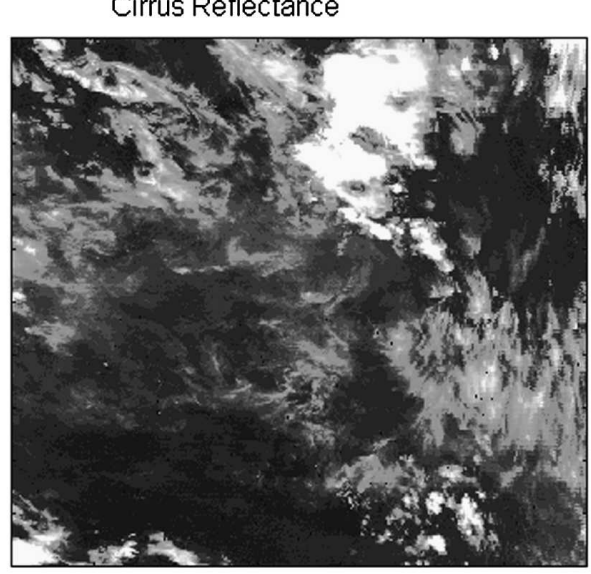

b)
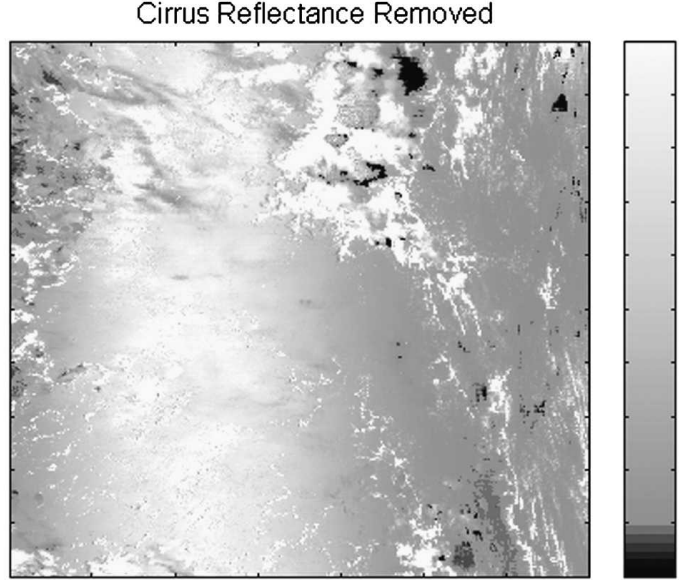

FIG. 8. Reflectance in the $0.65-\mu \mathrm{m}$ band attributed to (a) cirrus clouds and (b) with the cirrus reflectance removed from the MODIS subsection at 2350 UTC 4 Oct 2001.

$1.38-\mu \mathrm{m}$ reflectance much greater than $3 \%$ will be overestimated. This produced the very low reflectance patches in the figure, but did not affect AOD retrievals because pixels with the $1.38-\mu \mathrm{m}$ reflectance greater than $3 \%$ are screened out.

Removing the cirrus and surface contributions, as well as masking the areas of opaque cloud (black regions), where no retrievals were made, produced the $0.65-\mu \mathrm{m}$ residual reflectance field shown in Fig. 9a. With the exception of some darker regions, where the cirrus reflectance was overestimated, the residual reflectance field is fairly smooth with values near $1.5 \%$ even in most of the regions affected by sun glint. This resulted in the well-constrained retrieved AOD values seen in Fig. 9b.

Retrievals from the 50 pixel $\times 50$ pixel region centered on the Republic of Nauru were used for validation purposes because they most closely matched the time dependent ground measurements. The approximate $50-\mathrm{km}$ size of this region was chosen since it en- a)

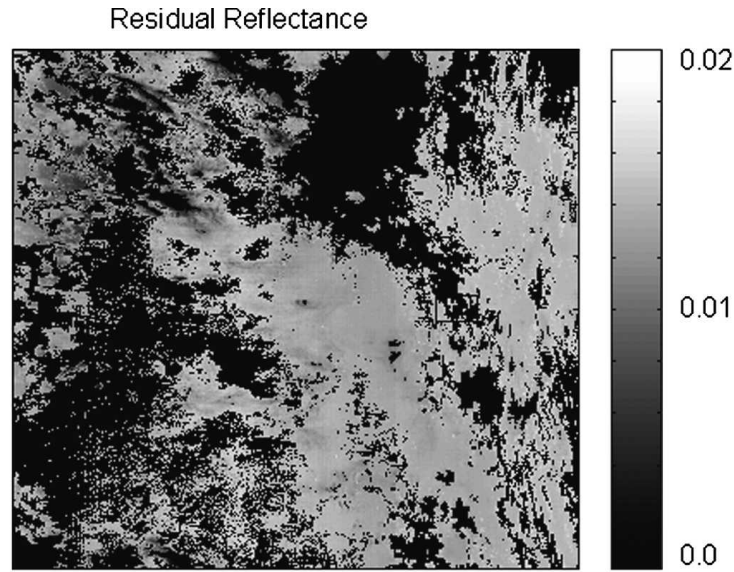

b)

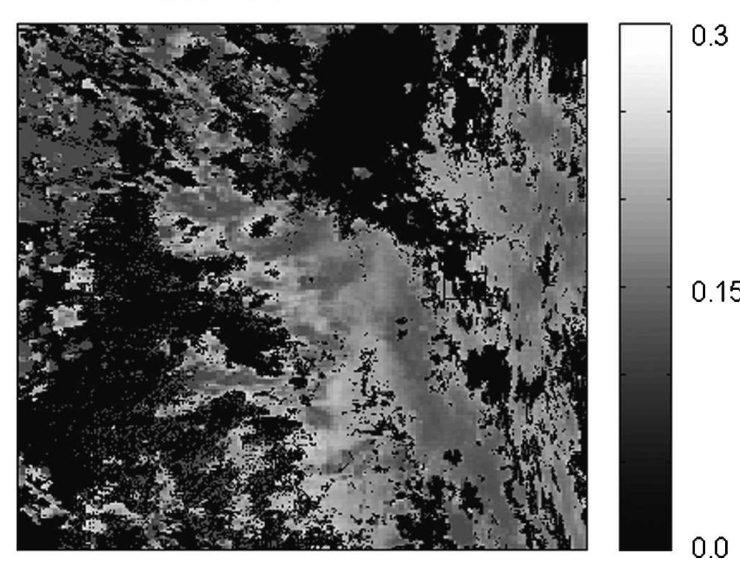

FIG. 9. From the MODIS subsection at 2350 UTC 4 Oct 2001: (a) residual reflectance in the $0.65-\mu \mathrm{m}$ band attributed to aerosols and (b) the retrieved aerosol optical depth.

gulfed the 1-h cirrus measurements of the cloud radar and the 3-h AERONET time series as calculated by cirrus and aerosol level (boundary layer) winds. In the first line of Table 4 the mean AOD and COD retrieval results are presented from this small region for the three TWP ARM cases. Mean MODIS retrievals from this region are shown in the second line. No MODIS AOD retrievals were made due to sun glint. In every case, the MODIS COD were well above the retrievals made by the scheme presented here and the ground data. The COD values determined by mmCR are given in the third line of the table. The range shown was produced by multiplying the mean vertical cloud thickness as measured by the mmCR during the 1 -h period centered on the MODIS overpass and the theoretical cirrus extinction coefficient as given in Liou (2002) for cirrus size distributions characterized by the effective ice crystal sizes of 10 and $42 \mu \mathrm{m}$. These radar-defined COD values were lower than both the retrieved and the MODIS values for the 13 September case, indicating 
TABLE 4. AOD and COD values determined by four methods for three TWP ARM cases.

\begin{tabular}{|c|c|c|c|c|c|c|}
\hline \multirow[b]{2}{*}{ Method } & \multicolumn{2}{|c|}{13 Sep 2001} & \multicolumn{2}{|c|}{22 Sep 2001} & \multicolumn{2}{|c|}{4 Oct 2001} \\
\hline & AOD & COD & AOD & COD & $\mathrm{AOD}$ & COD \\
\hline Retrievals ${ }^{\mathrm{a}}$ & 0.213 & 1.564 & 0.142 & 0.201 & 0.219 & 0.217 \\
\hline MODIS $^{\mathrm{b}}$ & N/A & 1.438 & $\mathrm{~N} / \mathrm{A}$ & 2.548 & N/A & 1.07 \\
\hline Radarc $^{\mathrm{c}}$ & N/A & $0.46-0.91$ & N/A & $0.2-0.3$ & N/A & $0.1-0.46$ \\
\hline AERONET $^{\mathrm{d}}$ & $0.16-0.29$ & N/A & $0.12-0.15$ & N/A & $0.17-0.3$ & N/A \\
\hline
\end{tabular}

${ }^{a}$ Retrieved values averaged from the $51 \times 51$ pixel region centered on the Republic of Nauru.

${ }^{\mathrm{b}}$ MODIS products averaged from the same $51 \times 51$ pixel region.

${ }^{\mathrm{c}}$ COD calculated by the product of the averaged 1-h millimeter-wave radar cloud thickness time series located on the republic on Nauru and theoretical extinction coefficients from Liou (2002).

d AOD from averaged 1-h AERONET data taken from the Republic of Nauru.

that satellite retrievals may have been influenced by the strong ocean glint. In the other two cases, the radardefined COD compares very well with the retrievals. In the forth line of the table, the AERONET AOD range is shown. These were determined from the range of all the AOD values available during the 3 -h period centered on the MODIS overpass. In each case, the retrieved AOD mean compares well with the AERONET values even in the first sun-glint case.

Figure 10 further shows how the retrieved values compare against the ground measurements for all three MODIS cases. The correlating mean values of the retrieved and radar measurements and the closest AERONET point to the MODIS overpass are shown as the diamonds and their respective uncertainties as extending lines. The length of the vertical lines from the mean point represent the standard deviation of the retrievals while the horizontal lines protrude outward to the maximum and minimum values of the ground measurements. The 13 September AOD comparisons (Fig. 10a) show good agreement in both mean and variance, but in the COD comparisons, much greater variance is seen in the retrieved values. Sun glint has already been identified as one possibility for this, but as can be seen from the mmCR time series in Fig. 6a, there was also a substantial amount of low clouds present that may have contaminated the cirrus retrievals. In actuality, only a few AOD pixel points located in the northeast away from the cloud location were retrieved. Also, large values of COD were seen just northwest of the island. These contributed most to the large retrieved variance and may not have actually been seen by the radar depending on the wind direction. No precise validation using only those points located along the wind vector could be performed in these cases.

Both the AOD and COD 22 September retrievals compare well to the ground measurements seen in Figs. $10 \mathrm{c}, \mathrm{d}$. AOD retrievals were made throughout the region except for the area of somewhat thicker cirrus in the west. The 4 October retrievals compare well against the ground measurements. Both the AOD and COD agreement is excellent in mean and variance (Figs. $10 \mathrm{e}, \mathrm{f})$. The distribution of retrieved AOD (5 pixel $\times 5$ pixel resolution) reveals that retrievals (Fig. 11a) were made under most of the thin cirrus identified, at 1 pixel resolution, but not in the opaque cloud regions that appear black in Fig. 11b.

The retrieval algorithm was also run on five consecutive MODIS (Terra) granules over the western Pacific Ocean in order to make broader comparisons with the retrieved MODIS AOD product. The five granules, presented in Fig. 12, extended from 2340 UTC 4 October 2001 to 0005 UTC 5 October 2001. The most northwestern point of the first granule (2340 UTC) had coordinates of $42.6^{\circ} \mathrm{N}, 157.0^{\circ} \mathrm{E}$ (near the Korean Peninsula) while the most southeastern pixel of the last granule was located at $49.9^{\circ} \mathrm{S}, 164.5^{\circ} \mathrm{E}$ (south of the midpoint between Tasmania and New Zealand). The only land surfaces contained in the first three granules were the small islands of the western Pacific, most notably the Solomon Islands. In the last two granules, Australia appeared in the lower left and upper left quarters, respectively. Retrievals were even performed over the land pixels possessing low surface reflectance (less than 10\%). Clear-sky reflectance was again determined for each granule as a function of sensor viewing angle, but with the separation of ocean from land. Surface reflectance was obtained by linearly interpolating the clear-sky reflectance in each sensor viewing angle bin using the middle scan line of adjacent granules as reference points.

The leftmost set of plots presents the retrieved AOD values produced by the algorithm specified in this paper while the rightmost set of plots shows the MODIS retrievals. Areas in which no AOD retrievals were generated are shown as dark. The region of sun glint, defined by the solar reflected angle less than $36^{\circ}$, is clearly noticeable in all five granules of the MODIS retrievals. 

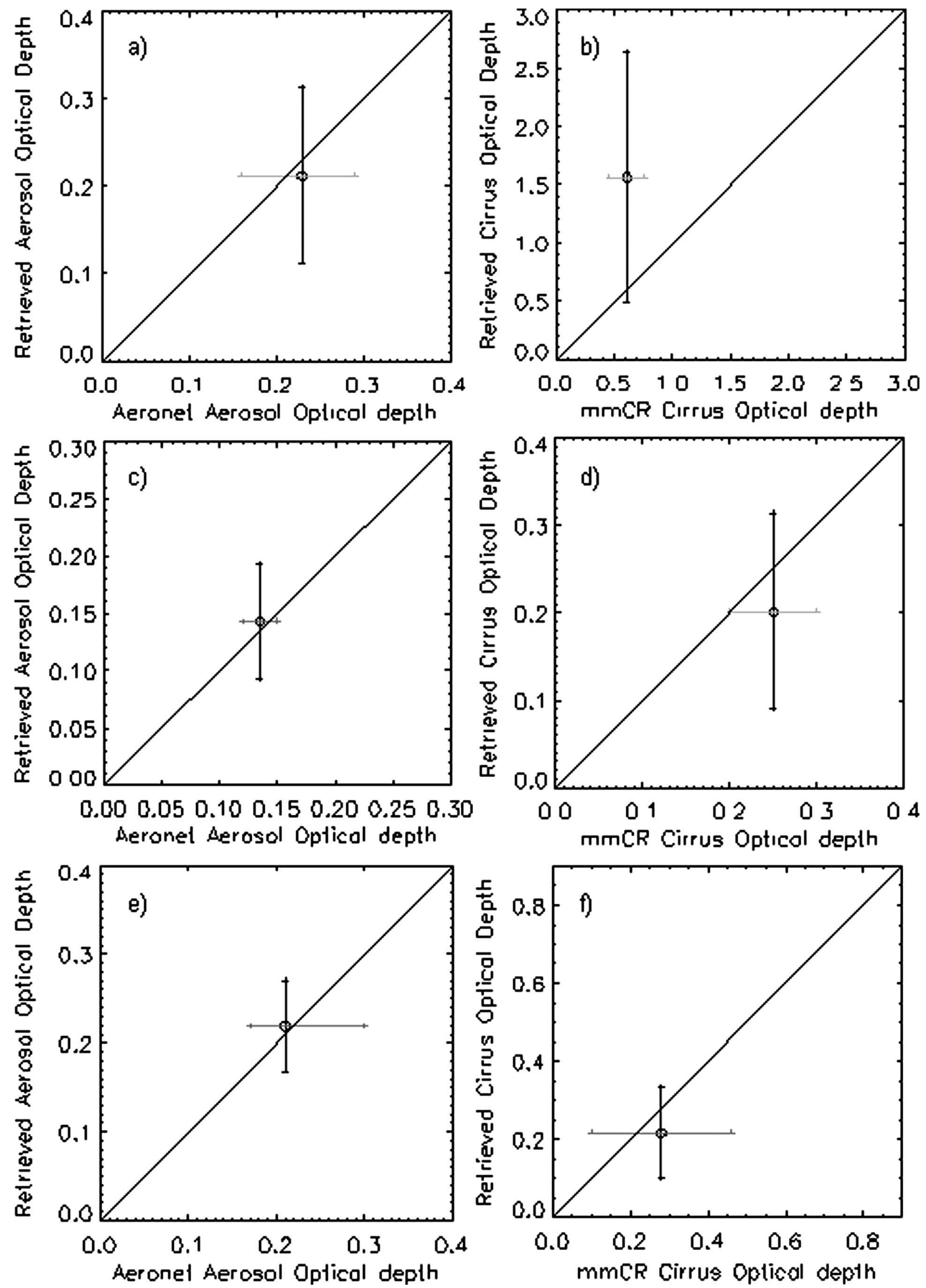

FIG. 10. Correlation between the AERONET and the retrieved AOD from the defined $51 \times 51$ pixel region on (a) 13 September, (c) 22 September, and (e) 4 October. (b), (d), (f) Also shown is the correlation between the cloud radar defined and the retrieved COD for the same three cases, respectively. 
a)

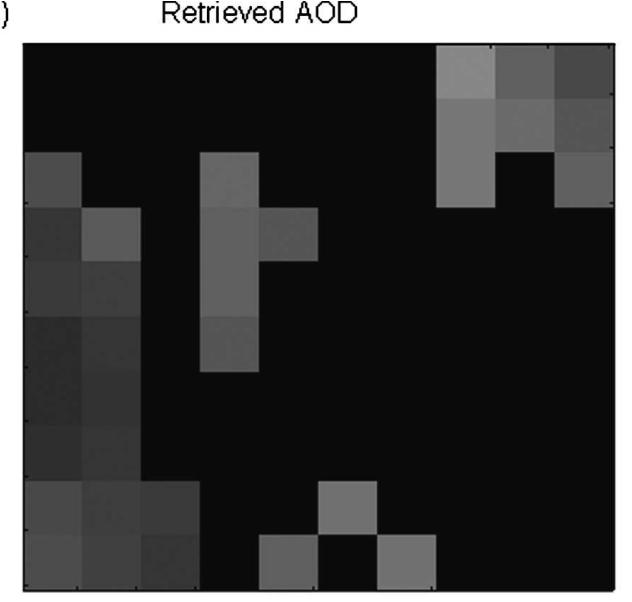

b)

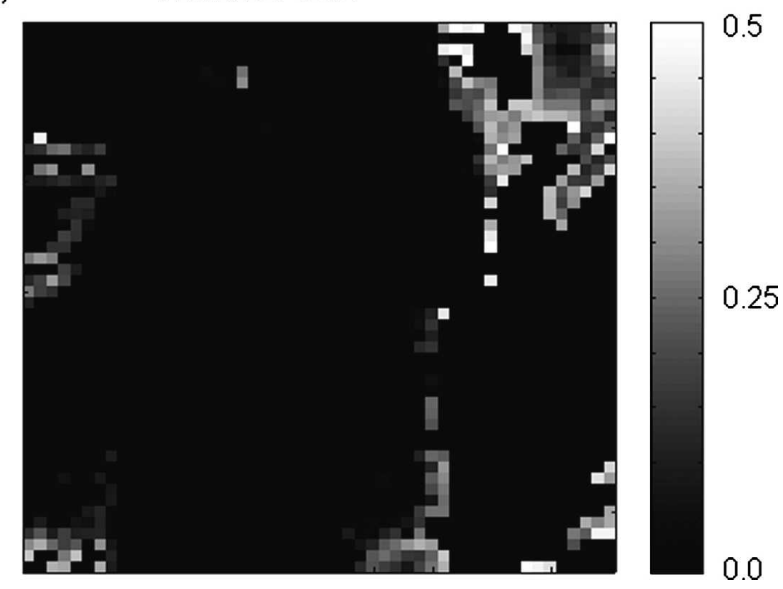

FIG. 11. Retrieved (a) AOD and (b) COD from the 50 pixel $\times$ 50 pixel region centered over the Republic of Nauru at 2350 UTC 4 Oct 2001.

This masked sun-glint region totals about $40 \%$ of the entire five-granule space. Our algorithm was able to produce seemingly consistent AOD values in the majority of the MODIS sun-glint region better described as mild sun glint (visible clear reflectance less than $10 \%$ ), although it appears that occasional bands of enhanced retrieved AOD values exist in these regions. This is most likely due to the added difficulty in characterizing surface reflectance where spectral sun glint exists. The last two granules contained the continent of Australia. In only in a few areas over land was AOD able to be retrieved by our algorithm (top left area of the bottom plot). MODIS AOD retrievals exist over a much broader area over this land region but seem to have outlined the coastline with enhanced values.

The mean retrieved AOD values for both our procedure and that of MODIS are presented for each of the five consecutive granules in Table 5. Also shown is the mean retrieved AOD for all of the iterations. The final mean AOD should be interpreted as the value corresponding to the highest iteration number. It can be seen that all five granules took no more than four iterations to converge to a final value. For most of the granules, the change from the initial to the final mean AOD value was less than $10 \%$. In each case, the MODIS retrievals showed a lower mean AOD than did our retrievals. This bias may be explained by the different methods used to estimate surface reflectance and the fact that retrievals were made inside mild sun-glint areas. The MODIS mean AOD values do lie within the expected uncertainty range for our retrievals as pointed out in Table 2. Cirrus contamination has been ruled out since the mean retrieved AOD values from our procedure were seen to be the same regardless whether cirrus were detected or not. It should be added that the MODIS retrievals produced about $50 \%$ more variance than did our retrievals, and that very small retrieved AOD values seemed to be responsible, in part, for producing their lower means.

Lastly, AOD retrievals were performed without removing the cirrus reflectance when the $1.38-\mu \mathrm{m}$ reflectance was less than $3 \%$. This simulated the effect that thin cirrus contamination would have on the AOD retrievals. The mean retrieved AOD values for each of the five consecutive granules were 0.15951, 0.20910, $0.24812,0.21853$, and 0.25165 , respectively. These results identify that thin cirrus contamination can introduce an error between 50\% and $100 \%$ in AOD retrievals.

\section{Conclusions}

A retrieval method that estimates the aerosol and thin cirrus contributions to the total atmospheric optical depth over ocean surfaces has been presented. This approach is based on the principal of radiative transfer and employs a parameterization of the atmospheric reflectance so that the contributions from cirrus, aerosol, and the surface can be separated. An accurate estimate of the surface reflectance as well as the precise removal of reflectance due to cirrus clouds is required. This was accomplished through careful interpretation of nearby clear-sky data and through an empirical method that correlates cirrus reflectance in the $1.38 \mu \mathrm{m}$ band to that of the two visible/near-infrared nonabsorbing channels. The algorithm was tested on a limited number of data and, therefore, can be considered most appropriate for regions of open-ocean where thin single-layer cirrus overrides marine aerosols away from strong sun glint where surface reflectance can be well characterized. The accuracy of this algorithm was demonstrated by the excellent mean retrieved AOD results found in the 50$\mathrm{km}$-square regions surrounding the ground instruments 
a)
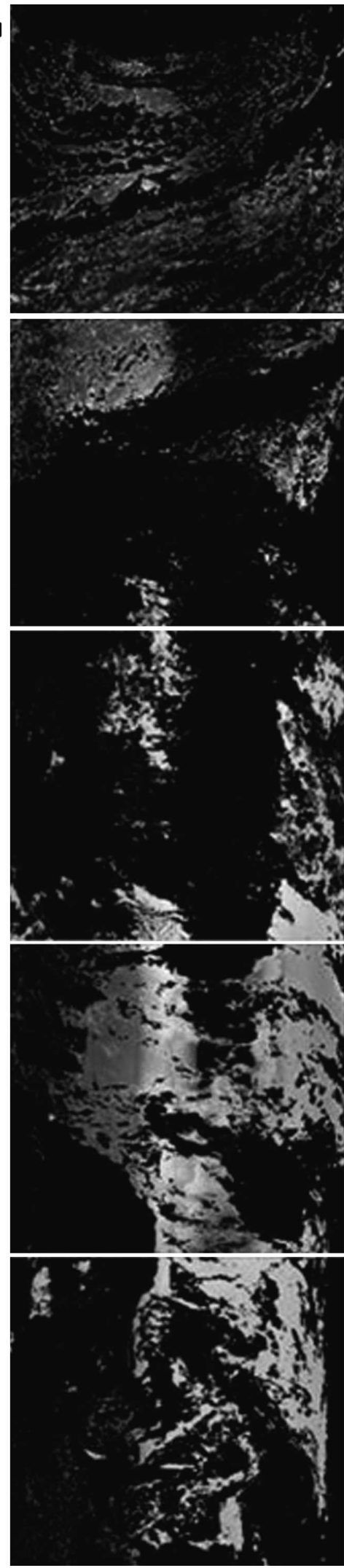

FIG. 12. Retrieved AOD for five consecutive MODIS granules on 4 Oct $(2340,2345,2350$, and 2355 UTC) and 5 Oct (0000 UTC) 2001. The left set (a) are the retrieved AOD values from the procedure described in this paper while the right set (b) are the MODIS retrievals. b)
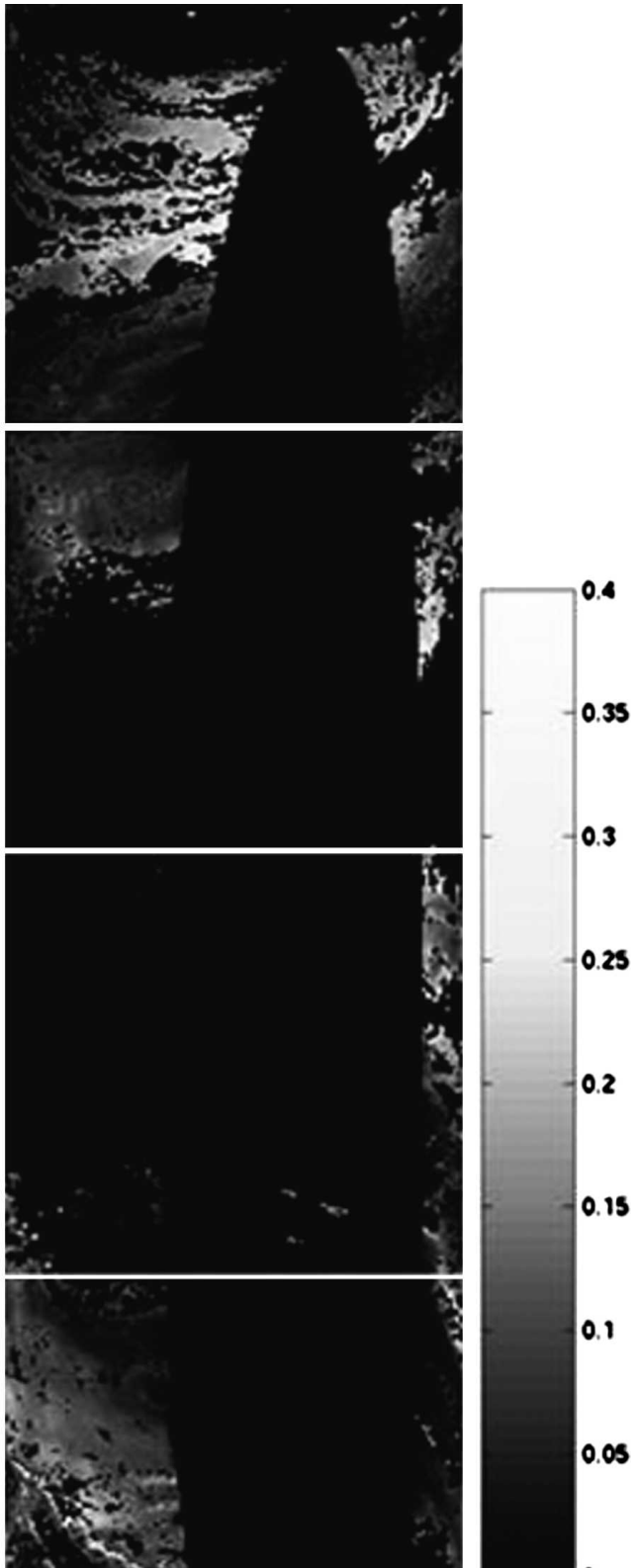

0.1

os 
TABLE 5. Mean granule-retrieved AOD given per iteration number. The last line shows the mean granule MODIS-retrieved AOD.

\begin{tabular}{cccccc}
\hline \hline Iteration & 2340 & 2345 & 2350 & 2355 & $\begin{array}{c}5 \text { Oct } \\
0000\end{array}$ \\
\hline 1 & 0.11198 & 0.12787 & 0.13695 & 0.13072 & 0.11430 \\
2 & 0.11578 & 0.12121 & 0.12377 & 0.12319 & 0.12150 \\
3 & 0.11576 & 0.12041 & 0.12337 & 0.12312 & 0.12117 \\
4 & - & 0.12048 & 0.12340 & - & 0.12112 \\
& & & & & \\
MODIS & 0.11268 & 0.08467 & 0.11000 & 0.09984 & 0.09828
\end{tabular}

that were used for validation located on the island republic of Nauru in the TWP ARM site. Even in mild sun-glint situations, limited AOD retrievals matched well to ground measurements within appropriate levels of uncertainty. These regions were known to contain both thin and relatively thick cirrus. The relatively thick cirrus, defined as possessing $1.38-\mu \mathrm{m}$ reflectance greater than $3 \%$, prohibited retrievals of both quantities, while the thin cirrus were taken into account by correcting for its contribution to the total top of the atmosphere reflectance.

The major conclusions identified by this study can be summarized as follows. First, the simultaneous retrieval of both AOD and COD in a single satellite field of view has been shown to be successful. Retrieved values of AOD and COD closely matched respective ground AOD measurements by AERONET sunphotometers and estimated COD values calculated by using millimeter-wave radar measured cirrus cloud thickness. In addition, the retrieved AOD compared well with MODIS retrievals for five consecutive granules spanning the $\mathrm{Pa}$ cific Ocean from $42^{\circ} \mathrm{N}$ to $50^{\circ} \mathrm{S}$.

Second, aerosol retrievals were made accurately in many regions of mild sun glint and in the presence of thin cirrus, thereby increasing the area of retrievable aerosol properties. Third, cloud contamination in AOD retrievals was shown to have decreased by as much as $100 \%$ by taking the thin cirrus reflectance into account. Fourth, most of the possible large retrieval error due to inaccurately classifying the cirrus ice crystal size distribution has been eliminated through the implementation of an iterative retrieval process that repeatedly adjusts the cirrus reflectance contribution based on successive effective particle size retrievals.

Finally, the largest source of remaining uncertainty is in establishing accurate values of surface reflectance. It was shown that retrieval errors could exceed $50 \%$ when AOD values fall below 0.1. This may be responsible for the slight bias seen in the comparisons between the mean AOD retrievals and the mean MODIS AOD values. The accuracy of the results produced by this tech- nique could be improved by better characterization of the ocean reflectance. Using smaller observational clear-sky regions in the proximately where retrievals take place would lower the observed variance due to specular reflectance change with scattering angle. In areas where nearby clear reflectance cannot be parameterized due to obstruction, state-of-the-art radiative transfer codes that model surface bidirectional reflectance would prove very useful. In addition, the use of denser angular lookup table grids will help capture the finer features of cirrus phase functions.

Acknowledgments. We thank Brent Holben from the NASA Goddard Space Flight Center for AERONET data obtained from http://aeronet.gsfc.nasa.gov. We obtained MODIS data from the NASA GES DAAC and millimeter-wave radar reflectivity data from the University of Utah Web site. This research was supported by DOE Grant DE-FG03-00ER62904, NASA Grant NNG04GG91G, and NSF Grant ATM-0331550.

\section{APPENDIX}

\section{Signal-to-Noise Ratio for Retrieving Aerosol Properties}

The SNR is defined by

$$
\mathrm{SNR}=\frac{\tau^{\text {est }}}{\mathrm{Ne} \Delta \tau},
$$

where $\mathrm{Ne} \Delta \tau$ is known as the noise equivalent differential spectral thickness, which is derived using known optical properties of a given aerosol type and $\tau^{\text {est }}$ is the estimated optical depth of the media. The noise equivalent differential spectral thickness can be written in terms of reflectance $(\rho)$ by using the single-scattering approximation appropriate for low optical depth as

$$
\mathrm{Ne} \Delta \tau=\operatorname{Ne} \Delta \rho \frac{4 \mu \mu_{0}}{\omega_{0} P(\Theta)},
$$

where $\mu$ and $\mu_{0}$ are the cosines of the sensor and satellite zenith angles, respectively, $\omega_{o}$ is the singlescattering albedo, $P(\Theta)$ is the phase function, and $\mathrm{Ne} \Delta \rho$ is defined as

$$
\mathrm{Ne} \Delta \rho=\operatorname{Ne} \Delta L \frac{\pi}{F_{0} \mu_{0}},
$$

where $F_{0}$ is the solar flux and $\mathrm{Ne} \Delta L$ is the noise equivalent differential spectral luminance with units of $\mathrm{W} \mathrm{m}^{-2}$ $\mu \mathrm{m}^{-1} \mathrm{sr}^{-1}$. To calculate the worse case, or lowest expected SNR, the $0.86-\mu \mathrm{m}$ band characteristics were examined, since the lowest expected aerosol optical depth should accompany the largest of the two ( 0.65 and 0.86 $\mu \mathrm{m})$ channels used. Following Tanre et al. (1988), an 
estimated optical depth of 0.05 was used for dust while 0.01 was used over the oceans. The noise equivalent differential spectral thickness was then maximized. The noise equivalent differential spectral luminance for this MODIS band is given as 0.009 (Kaufman and Tanre 1998). A nadir satellite viewing angle will produce the largest value for $\mu$ while the solar zeniths cancel out. Shettle and Fenn (1979) found that the minimum value of phase functions for maritime aerosols and dust, occurring near the $120^{\circ}$ scattering angle, were 0.08 and 0.05 , respectively. Last, a value of 0.7 was given as the minimum value of $\omega_{0}$.

\section{REFERENCES}

Ackerman, S. A., 1997: Remote sensing of aerosols using satellite infrared observations. J. Geophys. Res., 102, 17 069-17 079.

— with MODIS-Algorithm Theoretical Basis Document (MOD35). ATBD-MOD-06, Version 4.0, NASA Goddard Space Flight Center, 115 pp.

Chou, M.-D., P.-K. Chan, and M. Wang, 2002: Aerosol radiative forcing derived from SeaWiFS-retrieved aerosol optical properties. J. Atmos. Sci., 59, 748-757.

D'Almeida, G., P. Koepke, and E. Shettle, 1991: Atmospheric Aerosols: Global Climatology and Radiative Characteristics. A. Deepak, 561 pp.

Gao, B. C., and Y. Kaufman, 1995: Selection of the $1.375 \mu \mathrm{m}$ MODIS channel for remote sensing of cirrus clouds and stratospheric aerosols from space. J. Atmos. Sci., 52, 4231-4237.

— - — D. Tanre, and R.-R. Li, 2002: Distinguishing tropospheric aerosols from thin cirrus clouds for improved aerosol retrievals using the ratio of $1.38-\mu \mathrm{m}$ and $1.24-\mu \mathrm{m}$ channels. Geophys. Res. Lett., 29, 1890, doi:10.1029/2002GL015475.

Heymsfield, A. J., and C. M. R. Platt, 1984: A parameterization of the particle size spectrum of ice clouds in terms of the ambient temperature and the ice water content. J. Atmos. Sci., 41, $846-855$.

Houghton, J. T., Y. Ding, D. J. Griggs, M. Noguer, P. J. van der Linden, and D. Xiaosu, Eds., 2001: Climate Change 2001: The Scientific Basis. Cambridge University Press, $881 \mathrm{pp}$.

Kaufman, Y. J., and D. Tanre, 1998: Algorithm for remote sensing of tropospheric aerosol from MODIS (MOD04). ATBDMOD-02, NASA Goddard Space Flight Center, 85 pp.

King, M. D., S. C. Tsay, S. E. Platnick, M. Wang, and K. N. Liou, 1997: Cloud retrieval algorithms for MODIS: Optical thickness, effective particle radius, and thermodynamic phase (MOD06). ATBD-MOD-05, Version 5, NASA Goddard Space Flight Center, 85 pp.

Koepke, P., 1984: Effective reflectance of oceanic whitecaps. Appl. Opt., 23, 1816-1824.

Liou, K. N., 1986: Influence of cirrus clouds on weather and climate processes: A global perspective. Mon. Wea. Rev., 114, $1167-1199$.

— , 2002: An Introduction to Atmospheric Radiation. 2d ed. Academic Press, 583 pp.

_- Y. Takano, and P. Yang, 2000: Light scattering and radiative transfer in ice crystal clouds: Applications to climate research. Light Scattering by Nonspherical Particles: Theory, Measurements, and Applications, M. I. Mishchenko, J. W. Hovenier, and L. D. Travis, Eds., Academic Press, 417-449.
Lohmann, U., and E. Roeckner, 1995: Influence of cirrus cloud radiative forcing on climate sensitivity in a general circulation model. J. Geophys. Res., 100, 16 305-16 323.

McFarquhar, G. M., A. J. Heymsfield, J. Spinhirne, and B. Hart, 2000: Subvisual tropopause tropical cirrus: Observations and radiative impacts. J. Atmos. Sci., 57, 1841-1853.

Menzel, W. P., B. A. Baum, K. I. Strabala, and R. A. Frey, 2002: Cloud top properties and cloud phase algorithm theoretical basis document. ATBD-MOD-04, Version 6, NASA Goddard Space Flight Center, 62 pp.

Meyer, K., P. Yang, and B. C. Gao, 2004: Optical thickness of tropical cirrus clouds derived from the MODIS 0.66 and 1.375 $\mu \mathrm{m}$ channel. IEEE Trans. Geosci. Remote Sens., 42, 833-841.

Mishchenko, M. I., I. V. Geogdzhayev, B. Cairns, W. B. Rossow, and A. A. Lacis, 1999: Aerosol retrievals over the ocean by use of channels 1 and 2 AVHRR data: Sensitivity analysis and preliminary results. Appl. Opt., 38, 7325-7341.

Morel, A., and B. Gentili, 1993: Diffuse reflectance of oceanic waters. II. Bidirectional aspects. Appl. Opt., 32, 6864-6879.

Rao, N. X., S. C. Ou, and K. N. Liou, 1995: Removal of the solar component in AVHRR $3.7 \mu \mathrm{m}$ radiances for the retrieval of cirrus cloud parameters. J. Appl. Meteor., 34, 482-499.

Rolland, P., K. N. Liou, M. D. King, S. C. Tsay, and G. M. McFarquhar, 2000: Remote sensing of optical and microphysical properties of cirrus clouds using Moderate-Resolution Imaging Spectroradiometer channels: Methodology and sensitivity to physical assumptions. J. Geophys. Res., 105, 11 721-11 738.

Roskovensky, J. K., and K. N. Liou, 2003: Detection of thin cirrus from $1.38 \mu \mathrm{m} / 0.65 \mu \mathrm{m}$ reflectance ratio combined with 8.6-11 $\mu \mathrm{m}$ brightness temperature difference. Geophys. Res. Lett., 30, 1985, doi:10.1029/2003GL018135.

_,- , T. J. Garrett, and D. Baumgardner, 2004: Simultaneous retrieval of aerosol and thin cirrus optical depths using MODIS airborne simulator data during CRYTAL-FACE and CLAMS. Geophys. Res. Lett., 31, L18110, doi:10.1029/ 2004 GL020457.

Sassen, K., and B. S. Cho, 1992: Subvisual-thin cirrus lidar dataset for satellite verification and climatological research. J. Appl. Meteor., 31, 1275-1285.

Shettle, E. P., and R. W. Fenn, 1979: Models for the aerosol of the lower atmosphere and the effects of humidity variations on their optical properties. AFGL-TR-79-0214, Air Force Geophysical Laboratory, Hanscom AFB, MA, 94 pp.

Smith, W. L., S. Ackerman, H. Revercomb, H. Huang, D. H. DeSlover, W. Feltz, and L. Gumley, 1998: Infrared spectral absorption of nearly invisible cirrus clouds. Geophys. Res. Lett., 25, 1137-1140.

Takano, Y., and K. N. Liou, 1989a: Solar radiative transfer in cirrus clouds. Part I: Single-scattering and optical properties of hexagonal ice crystals. J. Atmos. Sci., 46, 3-19.

$\longrightarrow$, and $\longrightarrow$ 1989b: Solar radiative transfer in cirrus clouds. Part II: Theory and computation of multiple scattering in an anisotropic medium. J. Atmos. Sci., 46, 20-36.

$\_, \ldots$, and P. Minnis, 1992: The effects of small ice crystals on cirrus infrared radiative properties. J. Atmos. Sci., 49, 1487-1493.

Tanre, D., C. Devaux, M. Herman, R. Santer, and J. Y. Gac, 1988: Radiative properties of desert aerosols by optical groundbased measurements at solar wavelengths. J. Geophys. Res., 93, $14223-14231$.

Wylie, D. P., and W. P. Menzel, 1999: Eight years of high cloud statistics using HIRS. J. Climate, 12, 170-184. 